NBER WORKING PAPER SERIES

WAGE INDEXATION AND EXCHANGE MARKET INTERVENTION

IN A SMALL OPEN ECONOMY

Stephen J. Turnovsky

Working Paper No. 1170

NATIONAL BUREAU OF ECONOMIC RESEARCH

1050 Massachusetts Avenue

Cambridge MA 02138

July 1983

I wish to thank Joshua Aizenman, Richard Marston, two anonymous referees, and the Editor, Michael Parkin, for helpful comments on an earlier draft of this paper. The research reported here is part of the NBER's research program in International Studies. Any opinions expressed are those of the author and not those of the National Bureau of Economic Research. 


\title{
Wage Indexation and Exchange Market Intervention In a Small Open Economy
}

\begin{abstract}
The analysis of this paper stresses the interdependence between wage indexation on the one hand, and exchange market intervention on the other, as tools of macroeconomic stabilization policy in a small open economy subject to stochastic disturbances. It is shown how the choice of either policy instrument impinges on the effectiveness of the other. In particular, if the domestic money wage is fully indexed to some weighted average of the domestic and foreign price levels, then irrespective of what that chosen weight may be, exchange market intervention is rendered totally ineffective insofar as the stabilization of the real part of the domestic economy is concerned. Likewise, if the monetary authority intervenes in the exchange market so as to exactly accommodate for nominal movements in the demand for money, thereby rendering the excess demand for money dependent only upon real variables, then any form of wage indexation is totally ineffective for the stabilization of the real part of the system. In either polar case, the respective instrument can stabilize the domestic price level. Alternative combinations of policy for the stabilization for domestic and foreign disturbances are considered.
\end{abstract}

Stephen J. Turnovsky Department of Economics University of Illinois 1206 S. Sixth Street Champaign, Illinois 61820

(217) $333-2354$ 


\section{INTRODUCTION}

Recently, the issues of exchange market intervention on the one hand, and wage indexation on the other, have become topical in the international macroeconomic literature. To date, these questions have been analyzed virtually independently. The intervention literature has focused exclusively on non-indexed economies. That is, the models typically assume that nominal wages are fixed by a one period contract throughout the current period and therefore do not respond to current stochastic influences; see, e.g., Boyer (1979), Buiter (1979), Henderson (1979), Roper and Turnovsky (1980), Cox (1980), Turnovsky (1983). This 1iterature examines the extent to which alternative intervention policies-usually specified in terms of rules relating the current money supply and the current exchange rate--insulate the domestic economy from stochastic disturbances of varying origins. The issue of optimal intervention has also been discussed, although even for the simplest models, the derivation of optimal policies proves to be quite tedious. By contrast, the indexation models typically deal with the extreme regimes of perfectly fixed and perfectly flexible rates and study the extent to which alternative forms of wage indexation insulate the economy from various stochastic disturbances, under these two regimes. Optimal indexation schemes have also been discussed; see Flood and Marion (1982), Marston $(1982 a, 1982 b) .^{1}$

In fact, exchange market intervention and wage indexation are highly interdependent policy instruments. Both are intended to reduce the effects of current stochastic disturbances on the economy. The indexation scheme does so by adjusting the current nominal wage to these 
disturbances insofar as they are reflected by the price index governing the indexation scheme. The indexation rule therefore impinges directly on the supply function of the economy and hence it can be viewed as being a real form of policy intervention. By contrast, the intervention rule adjusts the money supply to the random disturbances insofar as they are reflected by the current exchange rate. Being a monetary rule, it is a nominal form of policy intervention.

In this paper we analyze the effectiveness of exchange market intervention and wage indexation as joint policy instruments. It is evident that by changing the slope of the supply function, the degree of wage indexation must influence the effectiveness of exchange market intervention and in turn the optimal degree of intervention. And the converse is also true.

Within the indexation literature, there is a debate concerning not only the appropriate degree of indexation, but also the appropriate price against which to index. While traditionally the consumer price index (CPI) is the chosen measure, it has been proposed that wage indexation schemes should be based on the movement of the domestic price index (the GNP deflator). It has been argued that this form of indexation will shield the domestic economy from increases in the prices of imported goods. ${ }^{2}$ In our analysis we shall allow for differential degrees of indexation to domestic and to foreign prices. We therefore consider three policy instruments; the two indexation parameters, together with the degree of exchange market intervention.

The framework we employ is a standard stochastic model of a small open economy under rational expectations; see, e.g., Cox (1980), 
Turnovsky (1981), Marston (1982a), etc. Our strategy is to solve the system for the relevant endogenous variables in terms of the stochastic disturbances and the three policy parameters. In principle, one could postulate an objective function and optimize simultaneously for the three policy parameters. This turns out to be intractable and we prefer to focus on the various disturbances individually and collectively and to consider how the degrees of intervention and indexation interact in neutralizing the influences of these disturbances on the economy. While the detailed results are discussed below, one conclusion is worth highlighting at the outset. First, if the current wage is fully adjusted to current price changes, in the sense that the sum of the degree of indexation to the domestic price change plus foreign price change is unity, then irrespective of the relative weights assigned to these two prices in the indexation scheme, exchange market intervention becomes totally ineffective in insulating the real part of the domestic economy from any stochastic disturbance. On the other hand, if the monetary authority intervenes in the exchange market so as to render the excess demand for nominal money balances dependent only upon real variables, then wage indexation becomes impotent in influencing real behavior. In either case, the respective policy will still retain influence over the nominal part of the system.

The remainder of the paper is structured as follows. The description of the model and its solution is outlined in Section 2. The interdependence between the two types of policy variables is discussed in Section 3. Sections 4 and 5 analyze the stabilization of domestic and foreign disturbances in turn, while the concluding section summarizes our main findings. Finally, certain computational details are given in the Appendix. 
2. THE MODEL

The country we consider is fully specialized in the production of a single (composite) commodity, part of which is consumed domestically, the remainder of which is exported. Domestic residents consume two goods, the domestic good and an imported good, the foreign price of which they take as given. There are two financial assets held in the portfolios of domestic residents. These include domestic money, which is non traded and a single bond which is traded internationally in a perfect bond market. The model is described by the following set of equations

$$
\begin{gathered}
Y_{t}=d_{1} Y_{t}-d_{2}\left[r_{t}-\left(C_{t+1, t}^{*}-C_{t}\right)\right]+d_{3}\left(Q_{t}+E_{t}-P_{t}\right)+u_{1 t} \\
0<d_{1}<1, d_{2}>0, d_{3}>0 \\
C_{t}=\delta P_{t}+(1-\delta)\left(Q_{t}+E_{t}\right) \quad 0<\delta<1 \\
M_{t}-C_{t}=\alpha_{1}\left(Y_{t}+P_{t}-C_{t}\right)-\alpha_{2} r_{t}+u_{2 t} \\
0<\alpha_{1}<1, \alpha_{2}>0 \\
r_{t}=\Omega_{t}+E_{t+1, t}^{*}-E_{t} \\
M_{t}-\bar{M}_{t}-\mu\left(E_{t}-\bar{E}\right) \\
Y_{t}=\gamma_{0}+\gamma\left(P_{t}-W_{t}\right)+u_{3 t} Y_{1}>0 \\
+W_{t, t-1}^{c}+T_{1}\left(P_{t}-P_{t, t-1}^{*}\right)+T_{2}\left(Q_{t}+E_{t}-Q_{t, t-1}^{*}-E_{t, t-1}^{*}\right)
\end{gathered}
$$

while for any variable $\mathrm{X}$ say,

$$
X_{s, t}^{*}=\varepsilon_{t}\left(X_{s}\right)
$$

where 


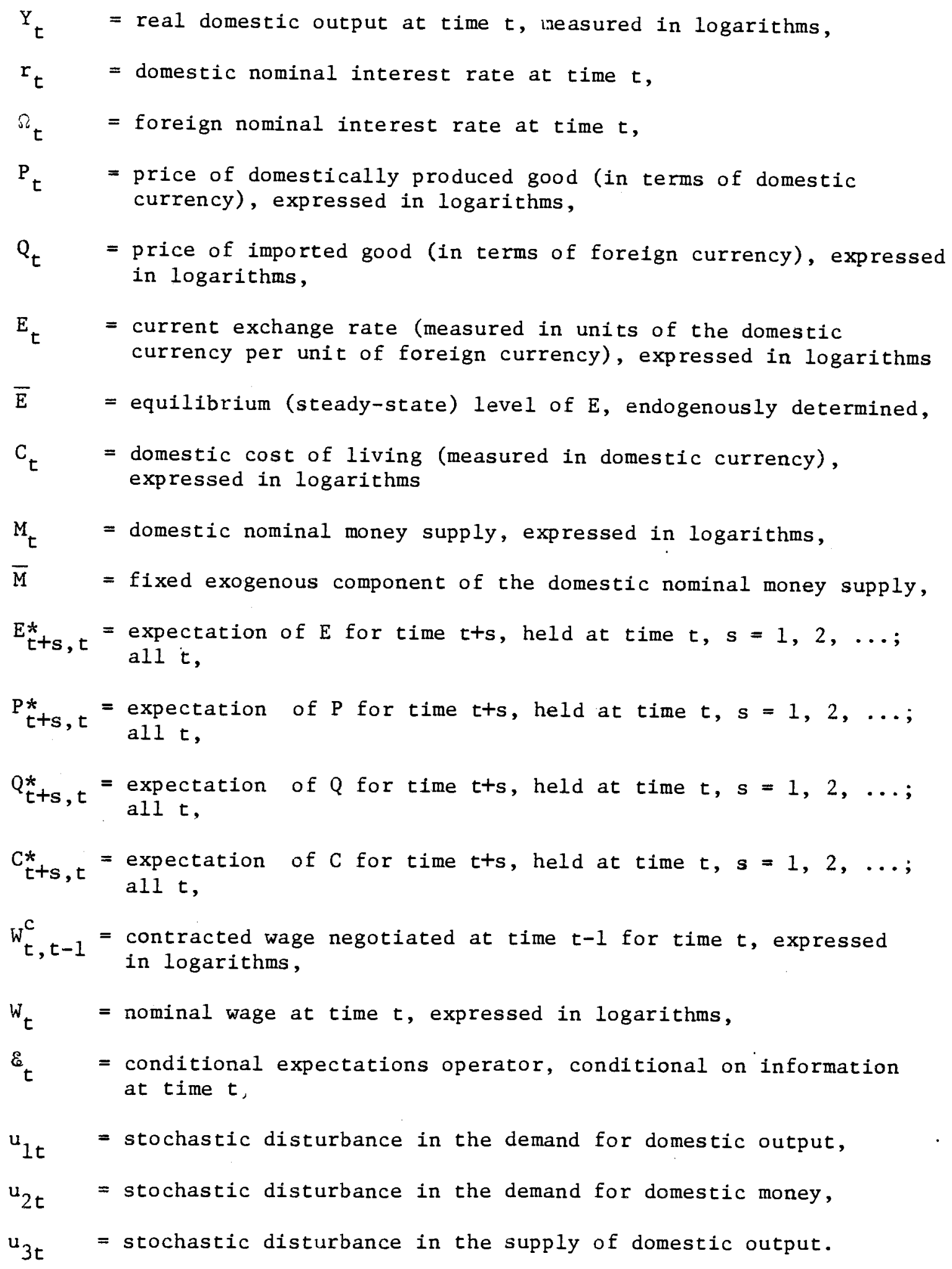


The first four equations are standard. Equation (la) describes the domestic economy's IS curve. Equation (1b) defines the domestic cost of living to be a log linear weighted average of the price of the domestic good and the domestic price of the imported good. The third equation specifies the domestic LM curve, while the assumption of perfect capital mobility is embodied in the uncovered interest parity condition (1d), which equates the expected rate of return on domestic and foreign bonds. ${ }^{3}$

The intervention policy is described by (le). This describes the degree of intervention by the authority as a function of the observed deviation from its long-run equilibrium level, which the authority is assumed to know. The limiting cases of $\mu=\infty, \mu=0$, correspond to fixed and flexible regimes, respectively, while any finite, non-zero. value of $\mu$ describes a managed float. The optimal intervention policy is to choose $\mu$ to optimize some specified objective, and as has been shown previously, an optimal policy may involve either $\mu>0$ or $\mu<0$, depending upon the primary source of the stochastic disturbances. Note that the reaction function (le) is expressed in terms of current values of $M$ and $E$, which are assumed to be instantly observable. 4

The supply side of the economy is described by equations (lf) and $(\mathrm{lg})$. The first of these is the short-run supply function, where $\gamma_{0}, \gamma$ are related to the underlying production function; see (4) below. The latter equation describes the current wage and the wage indexation scheme. ${ }^{5}$ At time $t-1$ a nominal wage rate $W_{t, t-1}^{c}$ is contracted for time $t$, based on information available up to time $t-1$; i.e., before the realizations of the stochastic disturbances at time $t$ are known. The 
critical information components include $\mathrm{P}_{t, t-1}^{*}$ and $\mathrm{C}_{\mathrm{t}, \mathrm{t}-1}^{*}$, the expectations of the prices of domestic output and the domestic CPI. At time $t$, when the actual prices become known, the current wage rate is adjusted in proportion to the difference between the actual and expected prices. The coefficient $\mathrm{T}_{1}$ describes the extent to which the wage rate is indexed to the current domestic price, $\mathrm{T}_{2}$ is the degree of indexation to the foreign price. Typically, $\mathrm{T}_{1}$ and $\mathrm{T}_{2}$ are constrained to lie in the range 0 to 1 , although this need not be optimal; see footnote 14 below. In short, the contract wage imposes a nominal short-run rigidity on the system, which the indexation scheme is intended, insofar as possible, to offset.

A number of special indexation schemes merit mention. If $\mathrm{T}_{1}>0, \mathrm{~T}_{2}=0$, the wage is indexed solely to the domestic price level, with $\mathrm{T}_{1}=1$ being full indexation. The case $\mathrm{T}_{1}=0, \mathrm{~T}_{2}>0$ describes indexation to the foreign price level, with $T_{2}=1$ being full indexation. Thirdly, if $\mathrm{T}_{1}=\mathrm{T} \delta, \mathrm{T}_{2}=\mathrm{T}(1-\delta)$, then noting (1b), (1g) becomes

$$
W_{t}=W_{t, t-1}^{c}+T\left(C_{t}-C_{t, t-1}^{*}\right)
$$

which describes indexation to the CPI. Full indexation occurs when $\mathrm{T}=1$, i.e., $\mathrm{T}_{1}=\delta, \mathrm{T}_{2}=(1-\delta)$. More generally, we shall say that the current wage is fully indexed if $\mathrm{T}_{1}+\mathrm{T}_{2}=1$. In this case (1g) becomes

$$
W_{t}=W_{t, t-1}^{c}+T_{1}\left(P_{t}-P_{t, t-1}^{*}\right)+\left(1-T_{1}\right)\left(Q_{t}+E_{t}-Q_{t, t-1}^{*}-E_{t, t-1}^{*}\right)\left(1 g^{\prime \prime}\right)
$$

This is equivalent to the wage being fully indexed to a weighted average of the domestic and foreign prices, the weights being $\mathrm{T}_{1}$ and $1-\mathrm{T}_{1}$, respectively. The first three schemes noted are just special cases of this general notion. 
The next step in the specification of the model is the determination of the wage contract $W_{t, t-1}^{c}$. Specifically we shall assume that this wage is set so that given the expectations of firms and workers, the labor market is expected to clear. Assuming that workers are concerned with their real wages in terms of the expected CPI, the expected supply of labor at the contract wage is

$$
N_{t, t-1}^{S}=a+b\left(W_{t, t-1}^{c}-C_{t, t-1}^{*}\right)
$$

Assuming further, a production function linking the logarithm of output to the logarithm of employment $N_{t}$ by

$$
Y_{t}=\varepsilon_{t}+\beta N_{t}
$$

where $E_{t}$ is a stochastic disturbance reflecting technological uncertainty, and having mean zero, it follows that the expected demand for labor $\mathrm{N}_{t, t-1}^{\mathrm{d}}$ (based on expected profit maximization) is determined by the marginal product condition

$$
\ln \beta+(\beta-1) N_{t, t-1}^{d}=W_{t, t-1}^{c}-P_{t, t-1}^{*}
$$

where firms value real wages in terms of their expected product price. The contract wage is determined by equating the expected demand and supply of labor appearing in (2a) and (2c), yielding

$$
W_{t, t-1}^{c}=\frac{\ln \beta+(\beta-1) a+(1-\beta) b C_{t, t-1}^{*}+P_{t, t-1}^{*}}{1+b(1-\beta)}
$$

Short-run actual employment is assumed to be determined by the short-run marginal productivity condition for firms, after the stochastic variables $\varepsilon_{t}, W_{t}$ and $P_{t}$ are realized, namely 


$$
\varepsilon_{t}+\ln \beta+(\beta-1) N_{t}=W_{t}-P_{t}
$$

Combining (2b) and $\left(2 c^{\prime}\right)$ we obtain the supply function

$$
Y_{t}=\frac{\beta \ln \beta}{1-\beta}+\frac{\beta}{1-\beta}\left(P_{t}-W_{t}\right)+\frac{\varepsilon_{t}}{1-\beta}
$$

which is of the form (1f), with $\gamma_{0} \equiv \beta \ln \beta /(1-\beta), \gamma \equiv \dot{\beta} /(1-\beta)$, $u_{3 t} \equiv \varepsilon_{t} /(1-\beta)$.

The three domestic stochastic variables $u_{1 t}, u_{2 t}$ and $u_{3 t}$ are assumed to have zero means, and finite variances

$$
\begin{aligned}
& \&\left(u_{i t}\right)=0 \quad i=1,2,3 \\
& \&\left(u_{i t}^{2}\right)=\sigma_{i}^{2} \quad i=1,2,3
\end{aligned}
$$

The two foreign variables in the system $\Omega_{t}, Q_{t}$ are also assumed to be random, being described by

$$
\begin{aligned}
& Q_{t}=\bar{Q}+q_{t} \\
& \Omega_{t}=\bar{\Omega}+\omega_{t}
\end{aligned}
$$

where $\bar{Q}, \bar{\Omega}$, are constant and

$$
\begin{gathered}
\&\left(q_{t}\right)=\&\left(\omega_{t}\right)=0 \\
\&\left(q_{t}^{2}\right)=\sigma_{q}^{2}, \&\left(\omega_{t}^{2}\right)=\sigma_{\omega}^{2}
\end{gathered}
$$

In addition, all random variables are assumed to be independently distributed over time, which means that $Q_{t+s, t}^{*}=\bar{Q}$. Also, for simplicity, we assume that domestic and foreign variables are uncorrelated, thereby enabling us to distinguish quite clearly between domestic and foreign stochastic influences. 6 


$$
-10-
$$

The model thus contains the eight equations (1a)-(1h), which jointly determine the eight endogenous variables $Y_{t}, r_{t}, E_{t}, M_{t}, P_{t}$, $C_{t}$, $W_{t}$ and $W_{t, t-1}^{c}$. These are determined on the assumption that the expectations appearing in the model are formed rationally. In order to analyze the model it is desirable to make several transformations:

(i) To reduce the dimensionality of the system we substitute from (lb), (1d), (lg) and (lh) to eliminate $r_{t}, c_{t}, w_{t}$ and $w_{t, t-1}^{c}$.

(ii) It is convenient to consider an initial equilibrium defined by assuming that all expectations are realized and setting all random variables to zero, thereby enabling us to incorporate all constants in the initial equilibrium.

(iii) We define the relative price of foreign to domestic goods (the inverse of the terms of trade) by

$$
S_{t}=Q_{t}+E_{t}-P_{t}
$$

Following these procedures, we can reduce the system to the four stochastic difference equations in the two real variables $y_{t}$, and $s_{t}$, and the two nominal variables $\mathrm{p}_{t}$ and $\mathrm{m}_{t}$, where lower case letters are used to denote deviations from the equilibrium; i.e., $e_{t} \equiv E_{t}-\bar{E}$, etc. These calculations are straightforward and details are relegated to the Appendix.

These equations involve the expectations of the relative price $s_{t+1, t}^{*}$ and the nominal price level $p_{t+1, t}^{*}$. The solution procedures for determining these expectations are familiar and are omitted. First, it can be shown that the only solution for the forecast of the relative price consistent with stability is $s_{t+1, t}^{*}=0$, for all $t .^{7}$ In the case of nominal price expectations it can be shown that the nature of the stable solution depends 
upon the intervention parameter $\mu$. If either $\mu>-1$ or $\mu<-\left(1+2 \alpha_{2}\right)$ the only solution consistent with stability is $\mathrm{p}_{t+1, t}^{*}=0$. However, for $-\left(1+2 \alpha_{2}\right)<\mu<-1$ the stable solution for $\mathrm{p}_{\mathrm{t}+1, t}^{*}$ turns out to be indeter-

minate. We resolve this indeterminacy by choosing the solution $p_{t+1, t}^{*}=0$. While this choice is arbitrary, it is simple and has the virtue of yielding a solution which is independent of the choice of intervention parameter $\mu .^{8}$

Thus setting all expectations to zero and substituting for the intervention rule, the system can be expressed in the following form

$$
\begin{gathered}
\left(1-d_{1}\right) y_{t}-\left(d_{2} \delta+d_{3}\right) s_{t}=u_{1 t}-d_{2}\left(\omega_{t}+q_{t}\right) \\
\alpha_{1} y_{t}+\left[(1-\delta)\left(1-\alpha_{1}\right)+\alpha_{2}+\mu\right] s_{t}+\left(1+\alpha_{2}+\mu\right) p_{t}=-u_{2 t}+\alpha_{2}\left(\omega_{t}+q_{t}\right)+\mu q_{t} \\
y_{t}+\gamma T_{2} s_{t}-\gamma\left(1-T_{1}-T_{2}\right) p_{t}=u_{3 t}
\end{gathered}
$$

which can be readily solved for $y_{t}, s_{t}$ and $p_{t}$.

\section{INTERDEPENDENCE BETWEEN EXCHANGE MARKET INTERVENTION AND WAGE INDEXATION}

The solutions for the endogenous variables of the small open economy are summarized in Table 1 . It is clear that these variables are linear functions of the random disturbances and in this table we list the coefficient attached to each disturbance. In Part A of the table we report the impact effects of the domestic disturbances, while the foreign disturbances are given in Part B. Notice that under a perfectly flexible rate regime $(\mu=0)$ the two foreign variables $\omega_{t}$ and $q_{t}$ have identical effects on the domestic variables. We therefore find it convenient to break down the foreign effects into $\left(\omega_{t}+q_{t}\right)$, and $\mu q_{t}$, the latter being an additional effect due to exchange market intervention. ${ }^{9}$ Thus denoting 
the two elements in the first row of Part $B$ by $\theta_{1}, \theta_{2}$, the effect of a unit increase in the foreign interest rate on $y_{t}$ is $\theta_{1}$, while that of a unit increase in the foreign price level $q_{t}$ is $\theta_{1}+\mu \theta_{2}$.

It is clear from Table 1 that $y_{t}, s_{t}$ and $p_{t}$ all fluctuate statically in response to the three domestic random variables ( $u_{1 t}, u_{2 t}$, $\left.\mathrm{u}_{3 t}\right)$ as well as the two foreign variables $\left(\mathrm{q}_{t}, \omega_{t}\right)$. The three policy parameters $\mu, T_{1}$ and $T_{2}$ influence the responses of all these endogenous variables to the exogenous random shocks in an interdependent way. The degree of wage indexation $T_{1}$ and $T_{2}$ influences the effectiveness of exchange market intervention $\mu$, and vice versa. In particular, the structure of the reduced form of the system, equation (7) enables us to derive the following important propositions:

(i) If the domestic wage rate is fully indexed in the sense that $T_{1}+T_{2}=1$, then irrespective of the relative magnitudes of $T_{1}$ and $T_{2}$, exchange market intervention becomes ineffective in insulating the real part of the domestic economy (summarized by $y_{t}$ and $s_{t}$ ) from any stochastic disturbances. Intervention policy, will still, however, be effective in influencing the nominal part of the domestic economy (summarized by $\mathrm{p}_{t}$ ).

(ii) If the monetary authority intervenes in the foreign exchange market so as to render the excess demand for nominal money balances dependent upon only the real variables, then wage indexation becomes totally ineffective in influencing the real part of the system. It will, however, still be able to influence the nominal variables. 
These two propositions can be immediately established as follows. If the domestic nominal wage rate is fully indexed, i.e., $T_{1}+T_{2}=1$, the domestic supply curve becomes independent of the domestic price level $p_{t}$. Rather, the two real variables $y_{t}$ and $s_{t}$ becomes jointly determined by the IS curve together with the supply function. They are therefore independent of the intervention parameter $\mu$, which impinges through shifts in the LM curve. But given $y_{t}$ and $s_{t}$, so determined, the domestic price level is determined in the domestic money market and therefore is a function of intervention.

On the other hand, if the monetary authority follows a policy of leaning with the wind and sets $\mu=-\left(1+\alpha_{2}\right)$, the excess demand for nominal money balances becomes independent of the price level and depends only upon the real variables $y_{t}$ and $s_{t}$. These variables become jointly determined by the IS curve, together with the LM curve and are therefore independent of the degree of wage indexation which impinges through the supply curve. Given $y_{t}$ and $s_{t}$, the price level is now determined by the supply function and is therefore dependent upon the degree of wage indexation. Note that any full wage indexation policy coupled with intervention in accordance with $\mu=-\left(1+\alpha_{2}\right)$ are mutually inconsistent and therefore infeasible.

The comparative static analysis with respect to the various policy parameters is tedious and is not pursued. Of greater interest is the question of the optimal choice of the policy parameters, $\mu, \mathrm{T}_{1}$ and $\mathrm{T}_{2}$. The typical approach to optimal policy questions in models such as this is to specify some objective function--frequently a weighted average of the variances of income and prices--and to choose the policy parameters to minimize this objective. ${ }^{10}$. While in principle this derivation is straightforward, in a model such as this it turns out to be 
complicated and not very illuminating. ${ }^{11}$ iore insight can be gained by focusing attention on the separate disturbances, taken both individually and in groups and examining the extent to which they can be eliminated by an appropriate package of policies. We proceed to consider the domestic and foreign disturbances in turn.

In general, it is not possible to stabilize exactly for all stochastic disturbances simultaneously through indexation and/or exchange market intervention. The reason is that the number of stochastic disturbances $\left(u_{1 t}, u_{2 t}, u_{3 t}, w_{t}\right.$ and $q_{t}$ ) exceeds the maximum number of contemporaneous pieces of information which may form part of the indexation or intervention rules. These include the exchange rate, the price of domestic output, the price of imported goods, and the domestic interest rate, although the latter has not been introduced into either of the rules we are considering. Thus our problen is closely related to the early work of Gray (1976). In her analysis she introduces two stochastic disturbances, a real and a monetary, and just one piece of contemporaneous information, the price of output, in her stabilization rule. She too, is therefore in general able to achieve only partial stabilization with respect to the two disturbances she considers. In a recent paper, Karni (1983) achieves full stabilization in the Gray model by indexing wages to output, as well as to price. But the fact that output quantities are typically less precisely observable than prices in the time frame envisaged by this type of analysis makes this form of indexation less appealing; see footnote 4.

Finally, we may note that we have restricted our analysis to just three policy parameters $\mu, T_{1}$ and $T_{2}$. It would, of course, be 
possible to make the money supply rule depend upon other contemporaneous variables such as the domestic interest rate, and the prices of domestic and foreign goods. This in turn raises the number of policy parameters, thereby increasing the range of possible ways of stabilizing for any given set of disturbances. However, the additional insight so obtained is insufficient to compensate for the added complications and accordingly, this aspect is not pursued.

\section{STABILIZATION OF DOMESTIC DISTURBANCES}

Suppose first that only stochastic disturbnace is in the demand for domestic output, $u_{1 t}$. It is evident that output can be stabilized against this form of stochastic disturbance--as indeed it can against other stochastic disturbances--in an infinite number of ways. Any combination of the policy parameters $T_{1}, T_{2}$ and $\mu$, satisfying the condition

$$
\left[(1-\delta)\left(1-\alpha_{1}\right)+\mu+\alpha_{2}\right]\left(1-\mathrm{T}_{1}\right)+\left[\alpha_{1}+\delta\left(1-\alpha_{1}\right)\right] \mathrm{T}_{2}=0
$$

will do, as long as they do not violate the condition that the Jacobian of (7), $D \neq 0.12$ If, for example, the wage rate is fully indexed to the price of domestic output alone $\left(\mathrm{T}_{1}=1, \mathrm{~T}_{2}=0\right)$, then $\mathrm{y}_{\mathrm{t}}$ is independent of $u_{1 t}$, irrespective of the degree of intervention. Alternatively, if the wage is indexed to the extent $\mathrm{T}$ to the $\mathrm{CPI}\left(\mathrm{T}_{1}=\delta \mathrm{T}, \mathrm{T}_{2}=(1-\delta) \mathrm{T}\right)$, then the required degree of intervention is

$$
\mu=-(1-\delta)\left(1-\alpha_{1}\right)-\alpha_{2}-\frac{\left[\alpha_{1}+\delta\left(1-\alpha_{1}\right)\right](1-\delta) T}{1-\delta \mathrm{T}}
$$

This equation highlights the tradeoff which exists between this form of wage indexation on the one hand, and exchange market intervention on the other. Any degree of indexation $T \geq 0$, calls for an intervention 
policy of leaning with the wind and the greater the degree of indexation the more intensive must this intervention be. ${ }^{13}$

The economic intuition for these policy responses can be seen from the basic equations (7). which when only stochastic disturbances $u_{1 t}$ are present and with partial indexation to the CPI, become

$$
\begin{gathered}
\left(1-d_{1}\right) y_{t}-\left(d_{2} \delta+d_{3}\right) s_{t}=u_{1 t} \\
\alpha_{1} y_{t^{*}}+\left[(1-\delta)\left(1-\alpha_{1}\right)+\alpha_{2}\right] s_{t}+\left(1+\alpha_{2}\right) p_{t}=-\mu\left(s_{t}+p_{t}\right)=-\mu e_{t} \\
y_{t}=-\gamma(1-\delta) T s_{t}+\gamma(1-T) p_{t}
\end{gathered}
$$

Suppose initially that there is no indexation and the exchange rate is perfectly flexible $(T=0, \mu=0)$. Then a positive disturbance in $u_{1 t}$ will cause both output $y_{t}$ and the price of domestic output $p_{t}$ to rise, the relative price $s_{t}$ will fall, and the exchange rate $e_{t}$ will appreciate; see Table 1.A. If the monetary authority responds to the appreciating exchange rate by decreasing the money supply, more of the fluctuations generated by $u_{1 t}$ are borne by the relative price and less by $y_{t}$ and $p_{t}$. In the case where the intervention follows the rule $\mu=-(1-\delta)\left(1-\alpha_{1}\right)-\alpha_{2}$, then $y_{t}$ and $p_{t}$ are jointly determined by the money market and supply function, which are free of stochastic fluctuations. This means that the relative price $s_{t}$ is determined by the IS curve and absorbs all the fluctuations in domestic output demand. If now the wage is partially indexed $(T>0)$, then given the above intervention, the fall in $s_{t}$ will be transmitted to a fall in output, via the indexation rule. To avoid this, the fall in $s_{t}$ must be offset by a rise in $p_{t}$ and this requires the monetary contraction to be increased; i.e., the degree of intervention must be intensified. 
Full indexation to the domestic CPI $(T=1)$ cannot achieve the perfect insulation of $y_{t} \cdot$ From $(9)$, this would require the intervention $\mu=-\left(1+\alpha_{2}\right)$ and as already noted, this is infeasible for any full indexation scheme. On the other hand, it has been noted that the perfect insulation of both domestic output and its price can be attained by setting $T=0$ and intervening in accordance with the rule $\mu=-(1-\delta)\left(1-\alpha_{1}\right)-\alpha_{2}$. Indeed, given this intervention rule, the same objective can be attained by setting $\mathrm{T}_{2}=0$, i.e., not indexing the wage to foreign price increases, regardless of the choice of $\mathrm{T}_{1}$. In this case all the fluctuations are absorbed by the relative price $s_{t}$. However, since none of the policy parameters impinge directly on aggregate demand, $s_{t}$ is independent of them. It is therefore impossible to stabilize all three variables $y_{t}$, $p_{t}$ and $s_{t}$ simultaneously, despite the fact that there are three policy instruments available. ${ }^{14}$

In the case of the monetary disturbance $u_{2 t}$, there is no such trade off between intervention and indexation insofar as the stabilization of output is concerned. One of two options is possible. First, $y_{t}$ can be stabilized by any full wage indexation rule $T_{1}+T_{2}=1$, when $s_{t}$ is also stabilized as well. This is because in this case the two variables become jointly determined by the IS curve and the supply function, both of which are independent of the monetary disturbance. However, the full indexation rule renders exchange market intervention ineffective, and intervention would be required to ensure the stability of $P_{t}$. The second, and superior alternative for eliminating the monetary disturbance, is simply to peg the exchange rate $(\mu=\infty)$. All the fluctuations in demand for money are accomnodated by the supply and $y_{t}, p_{t}$ and $s_{t}$ are stabilized perfectly; wage indexation is unnecessary. 
By contrast, complete stabilization for the supply disturbance $u_{3 t}$ is impossible. The only way $y_{t}$ and $s_{t}$ can be stabilized is by the intervention rule $\mu=-\left(1+\alpha_{2}\right)$, but this renders wage indexation ineffective. ${ }^{15}$ All the stochastic disturbances originating with domestic supply are absorbed by the domestic price level. In short, wage indexation is essentially ineffective as a policy rule for the purpose of stabilizing for domestic supply disturbances.

We now shift our focus slightly and consider the extent to which domestic income can be stabilized against the three domestic disturbances $u_{1 t}, u_{2 t}$ and $u_{3 t}$, when they occur simultaneously. Clearly, perfect stabilization against all three disturbances is impossible. To stabilize for $u_{3 t}$ would require intervention $\mu=-\left(1+\alpha_{2}\right)$, which renders wage indexation infeasible, and this would obviously be required to stabilize for either of the other disturbances. Hence, if the policy makers choose to stabilize for $u_{3 t}$, then they cannot stabilize for either of the other two disturbances.

By contrast, it is possible to stabilize $y_{t}$ for the two demand disturbances $u_{1 t}$ and $u_{2 t}$ simultaneously and indeed, this can be done in two ways. One possibility is to index the wage fully to only the domestic price $\left(\mathrm{T}_{1}=1, \mathrm{~T}_{2}=0\right)$, allowing the degree of exchange market interention to be arbitrary; another is to peg the exchange rate and fully index the wage to the price of domestic output $\left(\mu=\infty, T_{1}=1\right)$, allowing the degree of indexation to the foreign price level to be arbitrary.

To pursue this issue a little further, suppose that the only disturbances are on the domestic demand side, namely $u_{1 t}$ and $u_{2 t}$, and that the primary objective is to stabilize output exactly, and given that that is achieved, a secondary objective is to minimize the variance of 
the price of domestic output, $p_{t}$. If we assume that the stabilization of output is attained by the indexation scheme $T_{1}=1, T_{2}=0$, then the solution for $p_{t}$ is

$$
p_{t}=\frac{\left[(1-\delta)\left(1-\alpha_{1}\right)+\mu+\alpha_{2}\right] u_{1 t}-\left(d_{2} \delta+d_{3}\right) u_{2 t}}{\left(1+\alpha_{2}+\mu\right)\left(d_{2} \delta+d_{3}\right)}
$$

Assuming for simplicity that the two disturbances $u_{1 t}$ and $u_{2 t}$ are uncorrelated, then

$$
\sigma_{\mathrm{p}}^{2}=\frac{\left[(1-\delta)\left(1-\alpha_{1}\right)+\mu+\alpha_{2}\right]^{2} \sigma_{1}^{2}+\left(\mathrm{d}_{2} \delta+\mathrm{d}_{3}\right)^{2} \sigma_{2}^{2}}{\left(1+\alpha_{2}+\mu\right)^{2}\left(\mathrm{~d}_{2} \delta+\mathrm{d}_{3}\right)^{2}}
$$

Given that output is fully stabilized by fully indexing the wage to the domestic price, the optimal degree of exchange market intervention is obtained by minimizing (11) with respect to $\mu$, yielding the optimal policy

$$
\mu=-\left[(1-\delta)\left(1-\alpha_{1}\right)+\alpha_{2}\right]+\frac{\left(\mathrm{d}_{2} \delta+\mathrm{d}_{3}\right)^{2}}{\left[\delta\left(1-\alpha_{1}\right)+\alpha_{1}\right]^{2}} \frac{\sigma_{2}^{2}}{\sigma_{1}^{2}}
$$

Thus the optimal degree of exchange market intervention from the viewpoint of price stability as a secondary objective depends in part upon the relative variances of the two domestic disturbances. As polar cases, if $\sigma_{2}^{2}=0$ (i.e., there are only real demand disturbances) the optimal policy is to lean with the wind in accordance with $\mu=-\left[(1-\delta)\left(1-\alpha_{1}\right)+\alpha_{2}\right]$ while if $\sigma_{1}^{2}=0$ (i.e., there are only monetary disturbances) the optimum is to peg the exchange rate. Between these two extremes, the optimal intervention will involve leaning against the wind or leaning with the wind, depending in part upon the relative magnitudes of the two variances. Finally, it should be noted that the ability of either intervention policy or indexation policy to stabilize at least one endogenous variable perfectly for any single disturbance is a consequence of the 
following general characteristic. The current observation of certain market variables implies information as to the sources of the random shocks in the economy. For example, eliminating $y_{t}, p_{t}$ and $s_{t}$ from (7) and noting $\mathrm{m}_{t}=-\mu \mathrm{e}_{t}$, yields a linear relationship between $\mathrm{m}_{t}$ and $e_{t}$ of the form

$$
\mathrm{m}_{t}=\psi \mathrm{e}_{t}+\S_{t}
$$

where $\psi$ is a function of the known coefficients of the model and $\xi_{t}$ is a linear function of the unknown stochastic disturbances. The fact that $\mathrm{m}_{t}$ and $\mathrm{e}_{t}$ are observable to the monetary authority, who also are assumed to know $\psi$, means that they also observe the linear combination of random variables contained in $\xi_{t}$. When only one random variable is present, it follows that the observability of this linear combination reduces to the observability of the random variable itself. This may be appropriately offset, thereby maintaining perfect stability of at least one of the endogenous variables of the system. ${ }^{16}$ A similar argument applies in the case of the information assumed in the implementation of the indexation policy.

\section{STABILIZATION OF FOREIGN DISTURBANCES}

We now turn our attention to the foreign disturbances which impinge on the domestic economy through $q_{t}$ and $\omega_{t} \cdot$ Initially, we shall treat both of these separately, although as noted earlier, they are in fact jointly determined, reflecting more fundamental disturbances occurring abroad.

Domestic output can be stabilized against foreign price disturbances $q_{t}$ in a number of ways, the most direct being by fully indexing the wage rate to only the price of domestic output $\left(\mathrm{T}_{1}=1, \mathrm{~T}_{2}=0\right) .17$ 
This rule means that producers face a fixed real wage and in the absence of domestic supply disturbances, output is thereby fixed. Having indexed in this way, the domestic price level can then be stabilized for foreign price fluctuations by adopting the exchange market intervention policy

$$
\mu=\frac{d_{2}(1-\delta)\left(1-\alpha_{1}+\alpha_{2}\right)-\alpha_{2} d_{3}}{d_{3}-d_{2}(1-\delta)}
$$

This may involve leaning against the wind or leaning with the wind, depending upon parameter values. The intuition underlying this response can be seen from the basic equation (7), which with this full wage indexation scheme reduces to

$$
\begin{gathered}
\left(d_{2} \delta+d_{3}\right) s_{t}=d_{2} q_{t} \\
(1-\delta)\left(1-\alpha_{1}\right) s_{t}+\alpha_{2} e_{t}+p_{t}=-\mu e_{t}=m_{t}
\end{gathered}
$$

An increase in $q_{t}$ leads to an increase in the relative price $s_{t}$ and to an appreciation of the exchange rate $e_{t}$. Given that expectations are static, the appreciation in the exchange rate is equivalent to an increase in the domestic interest rate. The rise in the relative price $s_{t}$ leads to an increase in the demand for money, whereas the rise in the interest rate leads to a decrease. If the positive relative price effect dominates, then in order to stabilize the price level (i.e., prevent it from sharing some of the random fluctuations) the monetary authority should accommodate to the increase in the demand for money by increasing the supply. With the exchange rate appreciating such a policy is one of leaning against the wind. Conversely, if the negative interest rate dominates, then the net fall in the demand for money should be met with a net reduction; i.e, a policy of leaning with the wind. 
The response to eliminate fluctuations in the foreign interest rate $\omega_{t}$ are similar. Output can again be stabilized by the full indexation rule $T_{1}=1, T_{2}=0$, while given this form of intervention the price of domestic output can be stabilized by the intervention rule

$$
\mu=\frac{\alpha_{2} d_{3}-d_{2}(1-\delta)\left(1-\alpha_{1}+\alpha_{2}\right)}{d_{2}}
$$

The explanations are virtually identical to those just given for the foreign price disturbance and can be omitted.

In general, $q_{t}$ and $\omega_{t}$ are jointly stochastic. Irrespective of their source of variation abroad, and therefore their degree of correlation, domestic output can continue to be perfectly stabilized by fully indexing the wage to the price of domestic output $\left(T_{1}=1, T_{2}=0\right)$. With output stabilized in this way, the solution for $p_{t}$ is

$$
p_{t}=\frac{-\left(a+d_{2}\left(\mu+\alpha_{2}\right)\right)\left(\omega_{t}+q_{t}\right)+\left(d_{2} \delta+d_{3}\right) \mu q_{t}}{\left(1+\alpha_{2}+\mu\right)\left(d_{2} \delta+d_{3}\right)}
$$

where $a \equiv d_{2}(1-\delta)\left(1-\alpha_{1}\right)-\alpha_{2}\left(d_{3}+d_{2} \delta\right)$. Suppose now that as a secondary objective, the monetary authority chooses to intervene so as to minimize $\sigma_{p}^{2}$. Letting $z_{t} \equiv \omega_{t}+q_{t}$, the optimum degree of intervention is given by

$$
\mu=\frac{\left(a+d_{2} \alpha_{2}\right)\left[\left(1+\alpha_{2}\right)\left(d_{2} \delta+d_{3}\right) \sigma_{q z}-\left(d_{2}-a\right) \sigma_{z}^{2}\right]}{d_{2}\left(d_{2}-a\right) \sigma_{z}^{2}+\left(d_{3}+d_{2} \delta\right)^{2}\left(1+\alpha_{2}\right) \sigma_{q}^{2}+\left(d_{3}+d_{2} \delta\right)\left(a-2 d_{2}-d_{2} \alpha_{2}\right) \sigma_{q z}}
$$

where

$$
\sigma_{z}^{2}=\sigma_{\omega}^{2}+\sigma_{q}^{2}+2 \sigma_{\omega q} ; \sigma_{q z}=\sigma_{q}^{2}+\sigma_{\omega q}
$$

The optimal degree of indexation therefore depends not only upon the variances $\sigma_{\omega}^{2}, \sigma_{q}^{2}$, but also upon the covariance $\sigma_{\omega q}$, which in turn reflects the source of the disturbances abroad. A special case of interest arises 
if (i) the only foreign stochastic disturbances are monetary, and (ii) the foreign wage rate is fully indexed to the foreign price level. In that case it can be shown that

$$
z_{t} \equiv w_{t}+q_{t}=0
$$

and the optimal policy is therefore to set $\mu=0$; i.e., allow the exchange rate to float. ${ }^{18}$ Indeed, in this circumstance a perfectly flexible rate will stabilize both domestic output and the price of domestic output, irrespective of the degree of wage indexation domestically; see also Marston (1982a).

6. CONCLUSIONS

The analysis of this paper has stressed the interdependence between wage indexation on the one hand, and exchange market intervention on the other, as tools of macroeconomic stabilization policy in a small open economy subject to stochastic disturbances. We have shown how the choice of either policy instrument impinges on the effectiveness of the other. In particular, if the domestic money wage is fully indexed to some weighted average of the domestic and foreign price levels, then irrespective of what that chosen weight may be, exchange market intervention is rendered totally ineffective insofar as the stabilization of the real part of the domestic economy is concerned. Likewise, if the monetary authority intervenes in the exchange market so as to exactly accommodate for nominal movements in the demand for money, thereby redering the excess demand for money dependent only upon real variables, then any form of wage indexation is totally ineffective for the stabilization of the real part of the system. In either polar case, the respective instrument can stabilize the domestic price level. 
The following more specific conclusions have been obtained for the stabilization of domestic and foreign disturbances.

(i) There is an infinite number of combinations of wage indexation and exchange market intervention which will fully stabilize domestic output against domestic demand disturbances. Of these, the most satisfactory is to index the wage fully to (and only to) the price of domestic output. Exchange market intervention can then stabilize the price of domestic output, so that in fact the nominal and real wage are fixed.

(ii) Domestic output can be stabilized against domestic monetary disturbances by either fully indexing the wage to the price of domestic output or by pegging the exchange rate. Of these alternatives, the latter is optimal since it will stabilize all other variables, including the price of domestic output, as well.

(iii) The stabilization for domestic sppply disturbances is more difficult. Since wage indexation becomes totally ineffective, stabilization must be achieved through exchange market intervention and this can stabilize either domestic output or the domestic price level, but not both.

(iv) Domestic output can be stabilized for either foreign interest rate disturbances or foreign price disturbances, separately, by a combination of intervention and indexation policies. It can be stabilized for both disturbances simultaneously by fully indexing the wage rate to the price of domestic output. The domestic price can then be stabilized by exchange market intervention, the degree of which will depend upon the nature of the shock. 
While limitations imposed by considerations of analytical tractability have precluded the derivation of a complete optimal stabilization package, these results are suggestive of an intuitively appealing policy assignment rule. With the exception of domestic supply disturbances, they suggest that indexation policy should be directed toward the stabilization of output while exchange market intervention should be directed toward the attainment of price stability. 


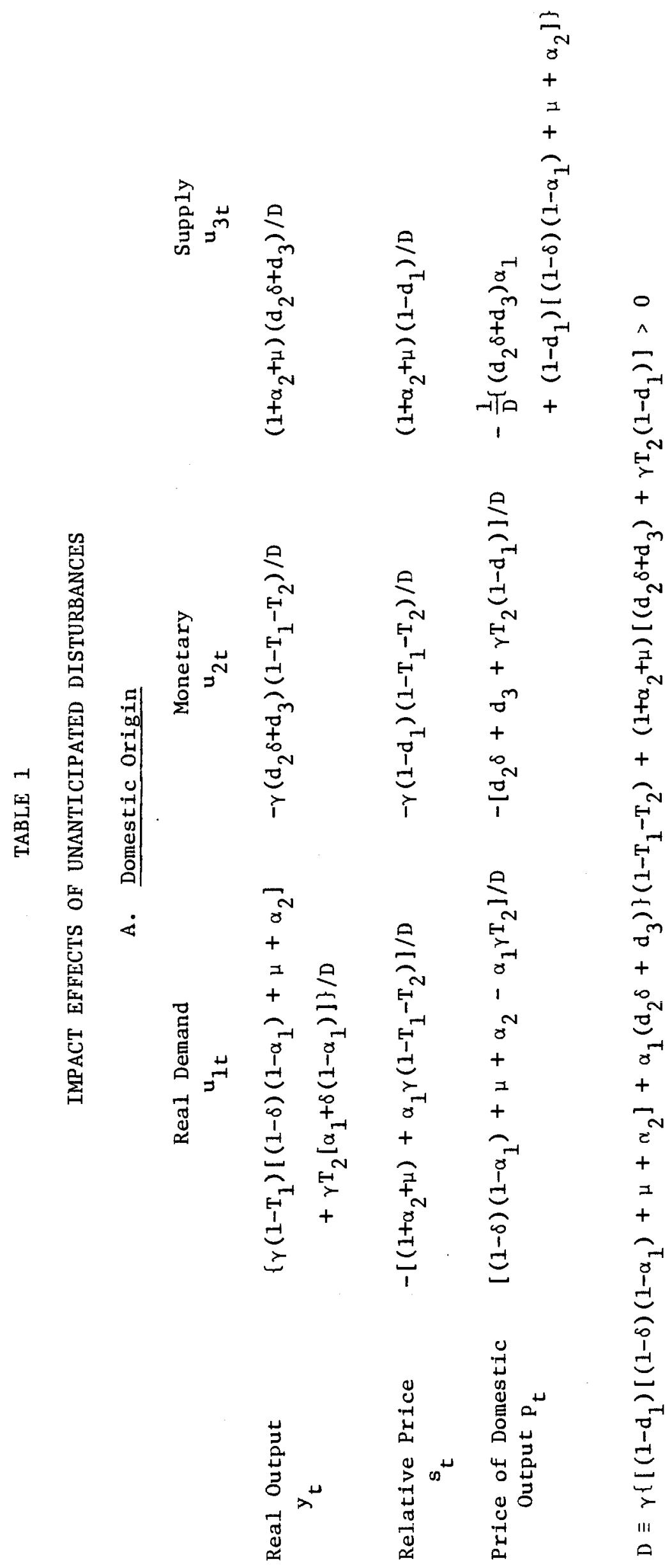



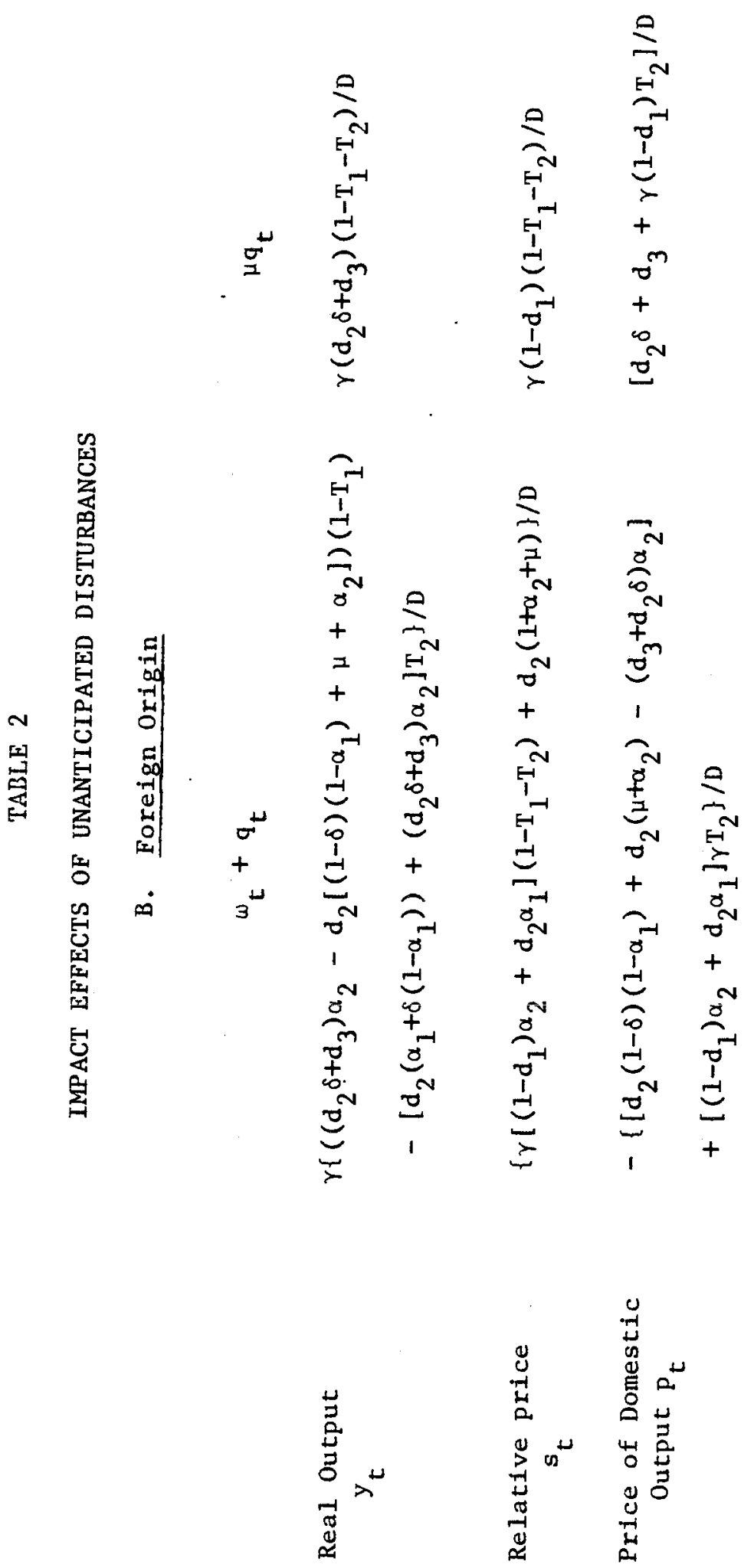
APPENDIX

\section{Derivation of Equations (7a)-(7c)}

We begin by substituting from (lb), (1d), (1g) and (1h) to eliminate $r_{t}, C_{t}, W_{t}$ and $W_{t, t-1}^{c}$. This yields the following four equations in the remaining variables $Y_{t}, E_{t}, P_{t}$ and $M_{t}$ and their relevant. expectations

$$
\begin{gathered}
\left(1-d_{1}\right) Y_{t}=-d_{2}\left[\Omega_{t}+\delta\left[\left(E_{t+1, t}^{*}-E_{t}\right)-\left(P_{t+1, t}^{*}-P_{t}\right)\right]-(1-\delta)\left(Q_{t+1, t}^{*}-Q_{t}\right)\right] \\
+d_{3}\left(Q_{t}+E_{t}-P_{t}\right)+u_{1 t} \\
Y_{t}=\frac{\beta[a+b \ln \beta]+\beta b(1-\delta)\left[P_{t, t-1}^{*}-Q_{t, t-1}^{*}-E_{t, t-1}^{*}\right]}{1+b(1-\beta)} \\
+\frac{\beta}{1-\beta}\left(1-T_{1}\right)\left(P_{t}-P_{t, t-1}^{*}\right)+\frac{\beta}{1-\beta} T_{2}\left[Q_{t}+E_{t}-Q_{t, t-1}^{*}-E_{t, t-1}^{*}\right]+u_{3 t} \\
M_{t}=\alpha_{1} Y_{t}+\left[\delta+\alpha_{1}(1-\delta)\right] P_{t}+\left(1-\alpha_{1}\right)(1-\delta)\left(Q_{t}+E_{t}\right)-\alpha_{2}\left[\Omega_{t}+E_{t+1, t}^{*}-E_{t}\right]+u_{2 t} \\
M_{t}-\bar{M}=-\mu\left(E_{t}-\bar{E}\right)
\end{gathered}
$$

We now define an initial equilibrium (denoted by bars) by assuming that all expectations are realized and setting all random variables at their means

$$
\begin{gathered}
\left(1-d_{1}\right) \bar{Y}=-d_{2} \bar{\Omega}+d_{3}(\bar{Q}+\bar{E}-\bar{P}) \\
\bar{Y}=\frac{\beta[a+b \ln \beta]+\beta b(1-\delta)(\bar{P}-\bar{Q}-\bar{E})}{1+b(1-\beta)} \\
\bar{M}=\alpha_{1} \bar{Y}+\left[\delta+\alpha_{1}(1-\delta)\right] \bar{P}+\left(1-\alpha_{1}\right)(1-\delta)(\bar{Q}+\bar{E})-\alpha_{2} \bar{\Omega}
\end{gathered}
$$


Subtracting (A.2) from (A.1) and using the definition

$$
s_{t} \equiv q_{t}+e_{t}-p_{t}
$$

together with the corresponding relationship in terms of expectations

$$
s_{t+1, t}^{*}=q_{t+1, t}^{*}+e_{t+1, t}^{*}-p_{t+1, t}^{*}
$$

yields

$$
\begin{gathered}
\left(1-d_{1}\right) y_{t}=-d_{2} \delta\left(s_{t+1, t}^{*}-s_{t}\right)+d_{3} s_{t}+u_{1 t}-d_{2}\left(q_{t}+\omega_{t}\right) \quad \text { (A.3a) } \\
y_{t}=-\frac{b \beta(1-\delta)}{1+b(1-\beta)} s_{t, t-1}^{*}+\gamma\left(1-T_{1}-T_{2}\right)\left(p_{t}-p_{t, t-1}^{*}\right) \\
\quad-\gamma T_{2}\left(s_{t}-s_{t, t-1}^{*}\right)+u_{3 t} \\
m_{t}=\alpha_{1} y_{t}+\left(1+\alpha_{2}\right) p_{t}+\left[\left(1-\alpha_{1}\right)(1-\delta)+\alpha_{2}\right] s_{t}-\alpha_{2}\left(s_{t+1, t}^{*}+p_{t+1, t}^{*}\right) \\
+u_{2 t}-\alpha_{2}\left(q_{t}+\omega_{t}\right) \\
m_{t}=-\mu\left(s_{t}+p_{t}-q_{t}\right) \quad\left(=-\mu e_{t}\right)
\end{gathered}
$$

Equations $(7 a)-(7 c)$ of the text are obtained by setting all expectations to zero (the rational expectations solution) and substituting for the intervention rule (A. 3d). 
FOOTNOTES

1. This literature in turn is an extension of the familiar closed economy model developed by Gray (1976) and Fischer (1977).

2. For a brief discussion see Marston (1982a), who cites various countries where such proposals have been considered.

3. For expositional convenience we assume that the income elasticity of the demand for money $\alpha_{1}<1$.

4. In discussing intervention policy it is important to distinguish between those variables which the authority can in effect currently observe, and those which at least in the short run are unobservable. Given that data on exchange rates and the money supply are available with much greater frequency than income figures, we shall assume that $E_{t}$ and $M_{t}$ are observable and that $Y_{t}$ is unobservable (at time $t$ ). This is one of the reasons why in general policy makers cannot stabilize output perfectly. The period of time for which this assumption is most applicable would be something like a month, since income is usually observed only quarterly and weekly money figures have considerable noise.

5. The wage indexation scheme assumes that the relevant prices are observable at least to the indexation authority, within the time period of observation.

6. Although $q_{t}, \omega_{t}$ are exogenous to the small country, they themselves are endogenously determined in the rest of the world, reflecting the various stochastic influences occurring abroad. It is thus evident that these variables will almost certainly be correlated, with the sign of thecorrelation depending upon the sources of the disturbances abroad; see Turnovsky (1983). 
7. This procedure of picking the stable root is typical of rational expectations models and is often justified on the grounds that the instability that would otherwise occur would be inconsistent with observed behavior. Alternatively, it is sometimes justified more formally by appealing to transversality conditions from appropriate optimizing models, which, provided the underlying utility function satisfies suitable restrictions, ensure that the expected price movements remain bounded; see, e.g., Brock (1974).

8. This result is proved by Turnovsky (1983).

9. The fact that shocks in the foreign nominal price level and foreign interest rate impinge identically on the domestic economy under a flexible exchange rate is of some interest. It operates through the domestic interest rate and stems from the fact that given the stationarity of exchange rate expectations, the interest rate parity condition simplifies to

$$
r_{t}=\omega_{t}-e_{t}=\left(\omega_{t}+q_{t}\right)-\left(s_{t}+p_{t}\right)
$$

10. Implicit in much of our discussion is the minimization of the variance of output as being the prime policy objective. Some authors, e.g., Marston (1982b), treat the minimization of the deviations from output which would result in the absence of contract lags as being the policy objective. There is also a new developing literature that models fluctuations as an equilibrium process, derived from utility maximizing behavior. Such fluctuations should not be confused with the welfare reducing deviations from some ideal path. See, e.g., Long and Plosser (1983) for further discussion of these issues. 
11. For an analysis which follows this approach, see Turnovsky (1983). The model considered is simpler than the present one in that it assumes perfect goods mobility (purchasing power parity). Even for that simple model the general expression for the optimal intervention turns out to be extremely complicated.

12. The expression for $D$ is given in Table 1 . We shall assume $D>0$.

13. Most of the policy discussions related to exchange market intervention are restricted to leaning against the wind, which intuitively would seem more appealing. The intuition behind why for certain disturbances leaning with the wind may be appropriate has been discussed elsewhere; see Turnovsky (1983). The case of leaning with the wind is also discussed in a somewhat different type of model by Buiter and Eaton (1980).

14. Note that if the policy objective is to stabilize the price of domestic output and the monetary authority chooses not to intervene in the exchange market, the optimal indexation policy is to set

$$
\mathrm{T}_{2}=\left[(1-\delta)\left(1-\alpha_{1}\right)+\alpha_{2}\right] / \alpha_{1} \gamma
$$

That is the wage must be indexed to the foreign price level. Moreover, the optimal degree of indexation in this circumstance may exceed unity.

15. For expositional convenience we assume that the income elasticity of the demand for money $\alpha_{1}<1$.

16. For some disturbances $p_{t}$ and $y_{t}$ move proportionately. In this case both can be stabilized simultaneously by the appropriate choice of a single policy instrument. 
17. It can be shown that like for domestic demand disturbnaces, that with full indexation to the domestic CPI, it becomes impossible to stabilize domestic output perfectly in the face of either foreign price or foreign interest rate disturbances. The reason is the familiar one. To achieve stability would require intervention $\mu=-\left(1+\alpha_{2}\right)$ which is infeasible, given full wage indexation.

18. This result is proved by Turnovsky (1983). 


\section{REFERENCES}

Boyer, R. (1978) "Optimal Foreign Exchange Market Intervention," Journal of Political Economy, 86, 1045-1056.

Brock, W. A. (1974) "Money and Growth: The Case of Long-Run Perfect Foresight," International Economic Review, 15, 750-777.

Buiter, W. (1979) "Optimal Foreign Exchange Market Intervention with Rational Expectations," in J. Martin and A. Smith, eds., Trade and Payments Adjustment under Flexible Exchange Rates, (London: Macmillan).

and J. Eaton (1980) "Policy Decentralization and Exchange Rate Management in Interdependent Economies," National Bureau of Economic Research Working Paper No. 531.

Cox, W. M. (1980) "Unanticipated Money, Output, and Prices in the Small Economy," Journal of Monetary Economics, 6, 359-384.

Fischer, S. (1977) "Wage Indexation and Macroeconomic Stability," in K. Brunner and A. Meltzer, eds., Stabilization of the Domestic and International Economy, (Amsterdam: North-Holland).

Flood, R. P. and N. P. Marion (1982) "The Transmission of Disturbances under Alternative Exchange Rate Regimes with Optimal Indexing," Quarterly Journal of Economics, 97, 43-66.

Gray, J. A. (1976) "Wage Indexation: A Macroeconomic Approach," Journal of Monetary Economics, 2, 221-235.

Henderson, D. W. (1979) "Financial Policies in Open Economies," American Economic Review, Papers and Proceedings, 69, 232-239.

Karni, E. (1983) "On Optimal Wage Indexation," Journal of Political Economy, $91,282-292$.

Long, J. B. and C. I. Plosser (1983) "Real Business Cycles," Journal of Political Economy, $91,39-69$.

Marston, R. C. (1982a) "Wages, Relative Prices, and the Choice Between Fixed and Flexible Exchange Rates," Canadian Journal of Economics, $15,87-103$.

Marston, R. C. (1982b) "Real Wages and the Terms of Trade: Alternative Indexation Rules for an Open Economy," Unpublished manuscript.

Roper, D. E. and S. J. Turnovsky (1980) "Optimal Exchange Market Intervention in a Simple Stochastic Macro Model," Canadian Journal of Economics, 13, 296-309.

Turnovsky, S. J. (1981) "Monetary Policy and Foreign Price Disturbances under Flexible Exchange Rates," Journal of Money, Credit, and Banking, $13,156-176$.

(1983) "Exchange Market Intervention Policies in a Small Open Economy," in J. Bhandari and B. Putnam, eds., Economic Interdependence and Flexible Exchange Rates, (Cambridge, Mass. MIT Press). 